\title{
The Effects of Team-Based Learning Education on Critical Thinking, Interpersonal Relationships, Self-Leadership and Academic Major Satisfaction
}

\author{
Suk-Young Lee ${ }^{1}$, Seung-Ju Kang ${ }^{2 *}$ \\ ${ }^{1}$ Dept. of Nursing Hanil University \& Presbyterian Theological Seminary, Korea \\ ${ }^{2}$ Dept. of Nursing Chunnam Techno University, Korea \\ ${ }^{1}$ sara27@daum.net, ${ }^{2}$ puoo7808@naver.com
}

\begin{abstract}
This study was conducted to develop and evaluate the effects of Team-Based Learning (TBL) education program, in the college course "Theory of Nursing Process, on critical thinking, interpersonal relationships, self-leadership and academic major satisfaction among nursing college students. The methodology used in this research is an experimental study of one group pre-post-test design, which was designed to check the difference before and after intervention through TBL education program to the treatment group. The participants in this study are second-year nursing students at H University in J city, South Korea. From March 24, 2019, to June 15, 2019, TBL education program was applied to "Theory of Nursing Process" classes 2 hours per week, 10 weeks in total. The collected data was analyzed with descriptive statistics and paired t-tests using the SPSS win 21. Program. The effects of TBL educational program on critical thinking ability, interpersonal relationships, self-leadership and satisfaction toward the nursing major were statistically significant, as follows: critical thinking ability $(t=-4.09, p=.000)$, interpersonal relationship( $t=-3.35, p=.001)$, self-leadership $(t=-3.48, p=.001)$ and major satisfaction $(t=-2.47, p=.016)$. The above findings confirm that the application of team-based learning in nursing education can positively affect critical thinking, interpersonal relationships and self-leadership among nursing students, and increase academic major satisfaction.
\end{abstract}

Keywords: TBL, Critical thinking, Interpersonal relationships, Self-leadership, Academic major, Satisfaction

\section{Introduction}

A major function of universities is to cultivate men of ability with knowledge-based training for satisfying the needs asked in their society. Furthermore, the goal of nursing education is to foster nurses who can deal with complicated and diversified situations by enhancing the ability to make decisions by themselves, and use critical thinking as a tool to solve problems that one may face in the clinical field. To achieve this goal, training nurses' capabilities to perform their duties successfully in the clinical field is the main agenda in education nursing.

\section{Background}

Article history:

Received (February 4, 2020), Review Result (March 15, 2020), Accepted (April 29, 2020) 
Team-Based Learning (TBL) is an academic instruction strategy for maximizing the performance between an individual and team by promoting interpersonal interaction prior to learning, and stimulating communication with team members in problematic situations [1]. TBL is an educational methodology to encourage students to learn effectively and enthusiastically by co-working within a small group, especially via team effort and continual individual learning [2]. TBL can help students enhance their capabilities within the complicated and diversified clinical field [3].

"critical thinking" in this context is defined as the ability to think clearly and rationally about information or opinions, and, if necessary, to seek more advanced opinions or alternatives considering comprehensive context [4]. The necessity of critical thinking is worth emphasizing in the knowledge-intensive information society.

In this study, "personal relationships" refer to the ability to establish a closer relationship and maintain this interaction [5]. Effective mutual cooperation in personal relationships can contribute to the development of learning efficacy and social attitude [6]. In such situations, TBL methodology proposes a solution by emphasizing the importance and value of personal relationships, delivering problem-solving oriented lectures, and offering an open environment for forming personal relationships.

This study defines "self-leadership" as an ability to lead or control oneself independently. Such leadership tends to encourage an individual to set goals by stimulating the function of this self-control system, and achieve goals with intrinsic motivation. Therefore, selfleadership can affect team members' attitude and performance positively [7]. Self-leadership is a key factor with which team members must be equipped, and as such, relates to TBL, especially on the mechanism of setting common learning objectives with team members and interacting with them to cope with a rapidly changing medical environment [8].

In this study, "academic major satisfaction" is a set of outcomes derived by comparing participants' career expectations with their university major. College students asserting higher satisfaction toward their major tends to adapt themselves to college life and life after graduation more effectively [9]. Academic major satisfaction entails a sense of accomplishment in education, which can affect students' academic achievement, peer cooperation in class, and adaptation to different environments [10]. As such, academic major satisfaction is a significant factor in TBL.

However, more researches on TBL are needed to prove these previous suggestions. In preexisting research on TBL, especially on nursing science, the following factors are considered: learner perceptions or academic achievement; participation or satisfaction in the class [11]. However, previous research on TBL does not sufficiently cover the effects TBL on critical thinking, interpersonal relationship, self-leadership, and academic major satisfaction.

This experimental research on the influence of TBL on critical thinking, interpersonal relationships, self-leadership, and academic major satisfaction in the college course "Theory of Nursing Process", a foundation subject in the nursing science curriculum, may be used to set up a methodology to lead a successful team learning and create an effective learning strategy.

\section{Research method}

\subsection{Research design}

This study is an experimental study of one group pre-post-test design, which was attempted to verify the effect of nursing course class to which was applied for TBL education program 
on critical thinking, interpersonal relationship, self-leadership, and major satisfaction of nursing students. This study was conducted on students of the Department of Nursing at $\mathrm{H}$ University in J, enrolling in second-year nursing courses.

The criteria for selecting study subjects are as follows: students who have no experience in the TBL program; have no physical or mental problems in their participation in education; understand the purpose and methods of this study and agree and sign up to participate in their own research. 70 students agreed to participate in the research, and 64 students, excluding four who did not respond to the post-survey after participating in the research, were included in the final analysis.

Teaching by TBL took place once a week, two hours per session, 10 weeks in total from March 24, 2019 to June 15, 2019. The individual abilities of students, such as interest in the subject, leadership, computer utilization, and presentation skills, were investigated according to the team's survey table and a team of seven to eight members was formed based on the survey. Prior to the class, students were given a range of study goals and reading assignments. The individual Readiness Test (IRAT) was presented with six questions of four different criteria for analyzing readiness and understanding based on a given reading task, and the Group Readiness Test (GRAT) was conducted through a group discussion with the same questions. In the case application phase, groups were asked to discuss the case and then present it, the professor supervised the discussion. In the last week of the team-based study, a peer review was initiated to prevent free-rides in team learning.

\subsection{Research tool}

\subsubsection{Critical thinking}

To measure critical thinking patterns, a critical thinking attitude measurement tool developed by Yoon Jin [12] was used. The tool comprises five questions of intellectual passion/attention, four questions of prudence, four questions of confidence, three questions of systematicness, four questions of intellectual fairness, four questions of sound skepticism, and three questions of objectiveness, adding up to 27 questions and seven factors in total.

\subsubsection{Interpersonal relationships}

This survey used the measure of friendship between young people modified by Jang [13]. The measure consists of 25 questions. In the context defined by Jang, friendship is divided and measured into seven sub-regions. The sub-area consists of satisfaction, sensitivity, trust, communication, understanding, intimacy, and openness.

\subsubsection{Self-readership}

Based on the questionnaire developed by Prussia et al [14] to measure self-preservation, the five behavioral strategies consist of five behavior-oriented questions such as "I tend to set goals in doing something," five cognitive strategy question.

\subsubsection{Academic major satisfaction}

In this study, the score was measured using the Majority Satisfaction Tool developed by Kim \& Ha [15] comprising a total of 16 questions. 
The Effects of Team-Based Learning Education on Critical Thinking, Interpersonal Relationships, SelfLeadership and Academic Major Satisfaction

\subsection{Data analysis}

The target data for this study was analyzed using the SPSS WIN 21.0 program. Descriptive statistics, the collected data was analyzed with descriptive statistics and paired t-tests and Pearson correlation coefficient were used for analysis.

\section{Results of the study}

4.1. Differences in critical thinking, communication ability, self-leadership, and Academic major satisfaction after applying TBL

After intervention through the TBL educational program, the average score of critical thinking ability increased by 7.58 points from $91.02 \pm 9.37$ before intervention to $98.59 \pm 11.11$ after intervention $(\mathrm{t}=-4.09, \mathrm{p}=.000)$. That of interpersonal relationship increased by 7.4 points from an average of $90.45 \pm 15.16$ before intervention to $98.20 \pm 12.81$ after intervention( $\mathrm{t}=$ $3.35, \mathrm{p}=.001$ ); self-leadership increased 4.52 points from $54 \pm 8.08$ before intervention to 58.52 \pm 7.33 after intervention $(\mathrm{t}=-3.48, \mathrm{p}=.001)$; major satisfaction increased by 3.64 points from $59.73 \pm 9.03$ before intervention to $63.36 \pm 7.98$ after intervention, and the difference was significant $(\mathrm{t}=-2.47, \mathrm{p}=.016)$. These results indicate that the TBL education program had meaningful effect on the participants [Table 1].

Table 1. Differences in critical thinking, communication ability, self-leadership, and Academic major satisfaction after applying TBL $(\mathrm{N}=66)$

\begin{tabular}{|c|c|c|c|c|c|}
\hline Variables & Pre test M \pm SD & $\begin{array}{c}\text { Post test } \\
\mathrm{M} \pm \text { SD }\end{array}$ & $\begin{array}{c}\text { Paired Differences } \\
\mathrm{M} \pm \text { SD }\end{array}$ & $\mathrm{t}$ & $\mathrm{p}$ \\
\hline Critical thinking & $91.02 \pm 9.37$ & $98.59 \pm 11.11$ & $-7.58 \pm 15.05$ & -4.09 & $.000^{* * *}$ \\
\hline $\begin{array}{c}\text { Interpersonal } \\
\text { Relationship }\end{array}$ & $90.45 \pm 15.16$ & $98.20 \pm 12.81$ & $-7.74 \pm 18.80$ & -3.35 & $.001 * * *$ \\
\hline Self-Leadership & $54 \pm 8.08$ & $58.52 \pm 7.33$ & $-4.52 \pm 10.54$ & -3.48 & $.001 * * *$ \\
\hline $\begin{array}{c}\text { Academic Major } \\
\text { satisfaction }\end{array}$ & $59.73 \pm 9.03$ & $63.36 \pm 7.98$ & $-3.64 \pm 11.97$ & -2.47 & $.016^{* *}$ \\
\hline
\end{tabular}

\subsection{Difference of critical thinking after $T B L$ education program $(N=66)$}

After mediation through the TBL educational program, intellectual justice $(\mathrm{t}=-2.55$, $\mathrm{p}=.013)$, sound skepticism $(\mathrm{t}=-2.16, \mathrm{p}=.034)$ and systematicness $(\mathrm{t}=-3.29, \mathrm{p}=.002)$ showed significant differences. There were no differences in intellectual honesty $(\mathrm{t}=.888, \mathrm{p}=.378)$, objectivity $(\mathrm{t}=-.49, \mathrm{p}=.625)$, and confidence $(\mathrm{t}=-.53, \mathrm{p}=595)$ [Table 2].

Table 2. Differences of critical thinking after TBL education program $(\mathrm{N}=66)$

\begin{tabular}{|c|c|c|c|c|c|}
\hline Variables & Pre test $\mathrm{M} \pm \mathrm{SD}$ & Post test $\mathrm{M} \pm \mathrm{SD}$ & $\begin{array}{l}\text { Paired Differences } \\
\mathrm{M} \pm \mathrm{SD}\end{array}$ & $\mathrm{t}$ & $\mathrm{p}$ \\
\hline Intellectual fairness & $8.15 \pm 1.06$ & $7.98 \pm 1.03$ & $.17 \pm 1.53$ & .888 & .378 \\
\hline prudence & $13.14 \pm 1.68$ & $13.95 \pm 1.89$ & $-.82 \pm 2.60$ & -.2 .55 & $.013 * *$ \\
\hline Objectivity & $11.60 \pm 1.39$ & $11.73 \pm 1.51$ & $-.12 \pm 2.00$ & -.49 & .625 \\
\hline healthy skepticism & $13.70 \pm 2.27$ & $14.55 \pm 2.36$ & $-.85 \pm 3.19$ & -2.16 & $.034 * *$ \\
\hline Systematicity & $6.08 \pm 1.41$ & $6.91 \pm 1.46$ & $-.83 \pm 2.06$ & -.3 .29 & $.002 * * *$ \\
\hline $\begin{array}{c}\text { Intellectual } \\
\text { eagerness/Curiosity }\end{array}$ & $6.85 \pm 1.42$ & $6.88 \pm 1.54$ & $-.03 \pm 2.05$ & -.12 & .905 \\
\hline Self Confidence & $7.20 \pm 1.32$ & $7.32 \pm 1.22$ & $-.12 \pm 1.84$ & -.534 & .595 \\
\hline
\end{tabular}




\subsection{Difference of interpersonal ability after TBL education programs}

Subareas of interpersonal relationships after intervention through the TBL training program, satisfaction $(\mathrm{t}=-2.51, \mathrm{p}=.015)$, sensitivity $(\mathrm{t}=-2.89, \mathrm{p}=.005)$, communication $(\mathrm{t}=-2.96$, $\mathrm{p}=.004)$, reliability $(\mathrm{t}=-2.16, \mathrm{p}=.034)$, openness $(\mathrm{t}=-3.24, \mathrm{p}=.002)$, comprehension $(\mathrm{t}=-3.19$, $\mathrm{p}=.002)$. All showed significant differences [Table 3].

Table 3. Differences of Interpersonal Ability after TBL education program $(\mathrm{N}=66)$

\begin{tabular}{|c|c|c|c|c|c|}
\hline Variables & Pre test $\mathrm{M} \pm \mathrm{SD}$ & Post test $\mathrm{M} \pm \mathrm{SD}$ & $\begin{array}{c}\text { Paired Differences } \\
\mathrm{M} \pm \mathrm{SD}\end{array}$ & $\mathrm{t}$ & $\mathrm{p}$ \\
\hline satisfaction & $14.53 \pm 2.85$ & $15.62 \pm 2.38$ & $-1.09 \pm 3.53$ & -2.51 & $.015^{* *}$ \\
\hline Sensitivity & $11.29 \pm 2.12$ & $12.20 \pm 1.73$ & $.91 \pm 2.56$ & -2.89 & $.005^{* *}$ \\
\hline communication & $14.44 \pm 2.79$ & $15.74 \pm 2.34$ & $-1.30 \pm 3.57$ & -2.96 & $.004 * * *$ \\
\hline trust & $10.73 \pm 2.26$ & $11.5 \pm 1.93$ & $-.77 \pm 2.90$ & -2.16 & $.034^{* *}$ \\
\hline intimacy & $11.05 \pm 2.36$ & $11.95 \pm 1.83$ & $-.91 \pm 2.62$ & -2.82 & $.006^{* *}$ \\
\hline openness & $13.97 \pm 2.78$ & $15.38 \pm 2.49$ & $-1.41 \pm 3.53$ & -3.24 & $.002^{* * *}$ \\
\hline Understanding & $14.45 \pm 2.64$ & $15.80 \pm 2.21$ & $-1.35 \pm 3.44$ & -3.19 & $.002^{* * *}$ \\
\hline
\end{tabular}

\subsection{Difference of self-leadership after TBL education programs}

Subareas of self-leadership after intervention through the TBL training program, behavioral Strategy $(\mathrm{t}=-3.25, \mathrm{p}=.002)$, cognitive strategy $(\mathrm{t}=-2.98, \mathrm{p}=.004)$, all showed significant differences [Table 4].

Table 4. Difference of self-leadership after TBL education programs $(\mathrm{N}=66)$

\begin{tabular}{|c|c|c|c|c|c|}
\hline Variables & Pre test $\mathrm{M} \pm \mathrm{SD}$ & Post test $\mathrm{M} \pm \mathrm{SD}$ & Paired Differences M \pm SD & $\mathrm{t}$ & $\mathrm{p}$ \\
\hline Behavioral Strategy & $32.20 \pm 5.39$ & $35.06 \pm 4.65$ & $-2.86 \pm 7.15$ & -3.25 & $.002 * * *$ \\
\hline Cognitive strategy & $21.80 \pm 3.40$ & $23.45 \pm 3.41$ & $-1.65 \pm 4.50$ & -2.98 & $.004 * * *$ \\
\hline
\end{tabular}
unit: $\mathrm{cm},{ }^{* * *}: p<0.005,{ }^{* *}: p<0.05$

\subsection{Correlations among critical thinking, interpersonal relationship, self-leadership, and academic major satisfaction TBL education programs}

After the intervention of the TBL education program, the correlations among the variables were found. Critical thinking and interpersonal skills $(\mathrm{r}=382, \mathrm{p}=.002)$, critical thinking and self-leadership ( $\mathrm{r}=.360, \mathrm{p}=.003)$, Critical thinking and major satisfaction $(\mathrm{r}=.534, \mathrm{p}=.000)$, interpersonal skills and self-leadership $(\mathrm{r}=.861, \mathrm{p}=.000)$, interpersonal skills and major satisfaction $(\mathrm{r}=.627, \mathrm{p}=.000)$, self-leadership and major satisfaction $(\mathrm{r}=.654, \mathrm{p}=.000)$ showed significant positive correlations [Table 5].

Table 5. Correlations among critical thinking, interpersonal relationship, self-leadership, and academic major satisfaction TBL education programs $(\mathrm{N}=66)$

\begin{tabular}{|c|c|c|c|c|}
\hline Variables & $\begin{array}{c}\text { Critical } \\
\text { thinking }\end{array}$ & $\begin{array}{c}\text { Interpersonal } \\
\text { Relationship }\end{array}$ & Self-Leadership & $\begin{array}{c}\text { Major } \\
\text { satisfaction }\end{array}$ \\
\hline Critical thinking & 1 & & & \\
\hline $\begin{array}{c}\text { Interpersonal } \\
\text { Relationship }\end{array}$ & $.382 * * *(.002)$ & 1 & & \\
\hline Self-Leadership & $.360 * * *(.003)$ & $.861 * * *(.000)$ & 1 & 1 \\
\hline $\begin{array}{c}\text { academic Major } \\
\text { satisfaction }\end{array}$ & $.534 * *(.000)$ & $.627 * * *(.000)$ & $.654 * * *(.000)$ & \\
\hline
\end{tabular}


The Effects of Team-Based Learning Education on Critical Thinking, Interpersonal Relationships, SelfLeadership and Academic Major Satisfaction

\section{Conclusion}

This study progressed to investigate the effects of TBL education program in the curriculum of Theory of Nursing Process on critical thinking skills, interpersonal relationships, self-leadership and academic major satisfaction. First, after intervention through TBL educational program, the average score of critical thinking ability increased by 7.58 points the difference was statistically significant $(\mathrm{t}=-4.09, \mathrm{p}=.000)$. This result shows the same result suggested by previous studies [2]. TBL's methodology is the process of problem solving by individuals' role allocation considering their prior learning and experience and communication with team members. Repeating these processes tend to enhance the critical thinking ability. According to this result, if more TBL education programs are applied in the curricula for nursing students, these students' critical thinking ability may be improved so that they can actively and reasonably solve problems which they are confronted in the clinical field after graduation.

Second, after intervention through TBL educational program, the average score of interpersonal relationship increased by 7.4 points and the difference was statistically significant $(\mathrm{t}=-3.35, \mathrm{p}=.001)$. This result shows the same result suggested by previous studies [16]. TBL education program affects positively interpersonal relationship especially in respecting and considering team members, and enhances students' abilities in interpersonal relationship. To improve and increase the usage of the interpersonal skills, TBL education program may be asked to be applied to other courses in the curricula for nursing students.

Third, after intervention through TBL educational program, the average score of selfleadership increased by 4.52 points from $54 \pm 8.08$ before intervention to $58.52 \pm 7.33$ after intervention, and the difference was statistically significant $(\mathrm{t}=-3.48, \mathrm{p}=.001)$. This result shows the same result suggested by previous studies [17]. Self-leadership acts as a major factor to improve the team's achievement by enhancing the team members' coordination and efficiency.

Fourth, after intervention through TBL educational program, the average score of major satisfaction increased by 3.64 points and the difference was statistically significant $(\mathrm{t}=-2.47$, $\mathrm{p}=.016$ ). In the process of TBL education program, more satisfaction of the class can be expected whenever team members show higher responsibility in preparing class material before entering the class, and promote co-working with other team members. Relating to TBL education program, the higher level of preparedness of class material can lead to more responsibility toward the team, and proactive immersion in class [18]. To increase the satisfaction of class participation during TBL education program, instructors tend to be asked to intervene in a manner that enhances the team members' participation equally.

By these results, in the Theory of Nursing Process course, the effect of TBL education program on nursing students' critical thinking ability, interpersonal relationship, selfleadership and major satisfaction shows positive correlations. During the 10 weeks of classes, TBL education program especially in small teams showed not just the effect of this program by preparing prior to class, but also a recommendable teaching-learning method for enhancing students' critical thinking ability, interpersonal relationship, self-leadership and academic major satisfaction.

It is worth noting that this study is carried out by a single case experiment with a sample group of one university nursing students, hence the limited nature of this study, especially in comparison to the control group or other teaching methods.

\section{References}


[1] L. K. Michaclscm, A. B. Knight, and L. D. Fink. (Eds.), "Team-based learning: A transformative use of small groups," Greenwood publishing group, (2004)

[2] H. S. Oh, "The effects of team-based learning on outcome based on nursing education," Journal of Digital Convergence, vol.3, no.9, pp.409-418, (2015)

[3] J. R. Han, "The effects of shared leadership on team performance and team commitment of team-based learning in nursing students: mediating effects of team trust," Journal of Digital Convergence. vol.14, no.12, pp.303-311, (2016)

[4] N. C. Facione, P. A. Facione, and C. A. Sanchez, "Critical thinking disposition as a measure of competent clinical judgment: The development of the California critical thinking disposition Inventory," Journal of Nursing Education, vol.33, no.8, pp.345-350, (1994)

[5] An M. S. and Choi S. H, "The relationship between interpersonal relationship and customer orientation with influencing factors in clinical nurses," Journal of the Korean Society of Living Environment System, vol.24, no.6, pp.865-873, (2017) DOI:10.21086/ksles.2017.12.24.6.865

[6] E. J. Yong and C. G. Kim, "Chul-gyu impact of interpersonal relationship ability, job stress, and stress copingtype on turnover intention of nurses in the early stage of their careers: focusing on job stress," Korean Journal of Occupational Health Nursing, vol.27, no.1, pp.36-47, (2018)

[7] B. C. Min, S. W. Lim, H. K. Kim, and H. S. Rhee, "The influence factors and effects of self-leadership: focusing on members of the hospitals health policy and management.," vol.23, no.1, pp.66-77, (2013)

[8] J. H. Kim and J. S. Chung, "Analyzing structural relationships between team leadership, team process and team effectiveness in project-based learning for engineering students," Journal of Educational Technology, vol.31, no.4, pp.909-948, (2015)

[9] H. S. Park, J. M. Yun, S. N. Lee, S. R. Lee, and M. S. Lee, "The relationship between self-efficacy, major satisfaction and career decision level of nursing students," J Health Info Stat, vol.43, no.1, pp.35-45, (2018)

[10] Y. S. Kim and E. J. Oh, "Relationship among emotional intelligence, critical thinking and major satisfaction in nursing students," J Korea Acad Industr Coop Soc, vol.17, no.7, pp.103-111, (2016)

[11] H. S. Han, "A study on nursing students' academic achievement and perception of team-based learning," Journal of Chungju National University, vol.46, pp.417-422, (2011)

[12] Yoon J., "Development of an instrument for the measurement of critical thinking disposition in nursing [doctoral thesis]," Catholic University, Seoul, http://www. riss.kr/link?id=T11531717, (2004)

[13] Chang H. S. and Choi B., "The effect of adolescent's background, family self-esteem, interprersonal relations disposition on etiquette implementation," Korea Family Resource Management Association, vol.13, no.2, pp.23-41, (2009)

[14] Prussia GE, Anderson JS, and Manz CC., "Self-leadership and performance outl-comes: the mediating influence of self-efficacy," J Organ Behav, vol.19. no.5, pp.523-538, (1998)

[15] K. H. Kim and H. S. Ha, “A study of department satisfaction factors of undergraduate students.," Korean J Counsel, vol.1, no.1, pp.7-20, (2000)

[16] S. J. Kim and M. S. Lee, "A case studies in the course of human relationship based on the problem-based learning," The Korea Society for Fisheries and Marine Sciences Education, vol.30, no.5, pp.1598-1609, (2018)

[17] H. J. Han, "The effects of shared leadership on team performance and team commitment of team-based learning in nursing students: mediating effects of team trust," Journal of Digital Convergence, vol.14, no.12, pp.303-311, (2016)

[18] E. J. Lee., "The effects of lessons using team-based learning on nursing students: focusing on pregnant women care," Asia-pacific Journal of Multimedia Services Convergent with Art, Humanities, and Sociology. vol.8, no.11, November, pp.685-696, (2018) 
The Effects of Team-Based Learning Education on Critical Thinking, Interpersonal Relationships, SelfLeadership and Academic Major Satisfaction

This page is empty by intention. 